\title{
Public trust requires disclosure of potential conflicts of interest
}

\section{Evidence that funding relationships can distort objectivity is growing - but money isn't the only source of bias.}

Sir - We commend your adoption of a policy that requires disclosure of financial interests and biases of authors who publish in Nature (Opinion, Nature 412, 751; 2001). Your effort to achieve transparency is an important response to the growing evidence of the adverse impacts that funding relationships can have on the integrity of science generally and on the reputations of individual institutions and researchers specifically.

More stringent conflict-of-interest policies are being adopted by universities, scientific societies and journals in the light of recent examples of publication and editorial interference by research funders; scientific misconduct; and even deaths of human testing volunteers. Several of the US medical schools receiving the most National Institutes of Health funding have been developing principles for conflict-ofinterest policies (Nature 408, 630; 2000), recommending full public disclosure of research funding when research results are presented or published.

For university policies to be effective, science journals must also adopt and enforce policies of full public disclosure of funding sources and other potential financial conflicts. Several medical journals have announced plans to adopt more stringent, uniform conflict-of-interest policies in response to increased collaboration between industry and universities.

We support Nature's leadership role in this extremely important issue, and challenge other scientific journals to adopt and enforce similar policies in a global effort to maintain public trust in the integrity of science.

Steven Gurney, Jennifer Sass

Health and Environment Program, Natural Resources Defense Council, 1200 New York Avenue NW, Suite 400, Washington, DC, 20005, USA

\section{Declaring interests in the fight for good science}

Sir - Scientists for Global Responsibility (SGR) welcomes with enthusiasm your new policy of asking authors to declare their financial interests (Opinion, Nature 412, 751; 2001). We congratulate Nature for taking a bold position on an issue of great importance.

SGR is particularly concerned that financial support from certain sources can skew the aims of research and distort the objectivity that is fundamental to good science. We have recently published a booklet entitled An Ethical Career in Science and Technology? (see http://www. sgr.org. uk/ethics.html). We hope that authors everywhere will support this policy and that scientists, their employers and those publishing their work will share the responsibility for ensuring an ethical approach to conducting and reporting scientific research.

One potential risk with a policy of voluntary disclosure is that a large proportion of authors may opt not to disclose. Yet mandatory disclosure risks penalising scientists who are contractually required to withhold information about their interests. Nature's approach may well be the best in the absence of a clear solution to this issue, but in the long term all science funding should be open to public scrutiny.

Vanessa Spedding

Scientists for Global Responsibility, PO Box 473, Folkestone CT20 1GS, UK

\section{Financial interests are not the only bias factor}

Sir-Personal financial interests (Opinion, Nature 412, 751; 2001) are relatively minor among the many factors relevant to potential bias. To think that bias will be meaningfully corrected by requesting disclosure of personal financial interests is naive or even harmful, as it could give a false assurance that bias has been checked.

No journal, Nature included, could ever guarantee the veracity of everything it publishes. In my experience, peer review simply screens gross and inappropriate statements; final or near-final answers come solely from the iteration of experiments in different hands. That is the only process of conditional verification known to science.

Nature has joined other special-interest publications in giving delusionary guarantees of veracity, rather than continually warning and helping readers to develop their own critical skills. A more mundane, but altogether more admirable, standard of publishing sincerity would be to print a disclaimer about implied standards of truthfulness on each issue's contents page. Gio Batta Gori

The Health Policy Center, 6704 Barr Road, Bethesda, Maryland 20816, USA

\section{Exciting future planned for birthplace of genetics}

Sir - Fabio Salamanca in his

Correspondence "Keeping Mendel in mind" (Nature 412, 118; 2001), responding to the News story "Museum suffers spiritual cramps over Mendel's work" (Nature 410, 6; 2001), expresses concern that the Mendel museum in the monastery in Brno is under threat. We would like to inform readers of an initiative to reinstate the monastery as a place of scientific discovery.

The proposal is that the monastery site could eventually house a research institute, a conference centre with a modern lecture hall and a museum of genetics, as well as providing courses for graduates and schoolchildren alike. It could create a forum for discussions on genetics and the wider ethical issues. Abbot Evzen Martinec has agreed that much of the site could be adapted to this end, if the funds could be found, and the city of Brno is keen to use the redevelopment of the site as a focus for urban renewal. President Vaclav Havel has given the project his full support.

Plans for the first exhibition in 2002 are going ahead, initiated by Old Brno monastery and curated by Marina Wallace and Martin Kemp in collaboration with the Mendelianum, Brno. An inaugural conference, "Genetics after the Genome", will be held concurrently.

Although seed money is available for a pre-feasibility study to be overseen by the architect Eva Jiricna, more money is needed for the project. Further information can be obtained from anna@nt.imp.univie.ac.at.

Kim Nasmyth ${ }^{\star}$, Dieter Schweizer $\dagger$ ${ }^{\star}$ Research Institute of Molecular Pathology, Dr Bohrgasse 7, A-1030 Vienna, Austria $\dagger$ Institut für Botanik der Universität Wien, Abteilung für Zellbiologie und Genetik, Rennweg 14, A-1030 Vienna, Austria

\section{Debate over language's link with intelligence}

Sir-M. Piattelli-Palmarini, in his review (Nature 411, 887-888; 2001) of the book Pathways to Language, criticises authors Kyra Karmiloff and Annette KarmiloffSmith for misrepresenting the linguistic 
and cognitive abilities of children with Williams syndrome (WMS). Contrary to the book's authors, your reviewer claims that "children with Williams syndrome have a barely measurable general intelligence" but "an exquisite mastery of syntax and vocabulary", although they are "unable to understand even the most immediate implications of their admirably constructed sentences".

Based on our own extensive research on WMS in English and Italian, we disagree with your reviewer. First, intelligence is certainly testable in WMS. In older children, the average performance IQ is around 60 , and many score much higher. By the age of 8-10 years, children with WMS are typically functioning at a mental age of 5-6, an age at which normally developing children display sophisticated vocabulary and complex grammar.

Second, syntax is far from perfect in WMS. In younger children, lexical and grammatical development are delayed; in older children, difficulties and errors persist. Overall levels of syntax never exceed mental age.

Third, comprehension abilities in WMS are often puzzling, but they are much more sophisticated than PiattelliPalmarini implies. Individuals with WMS are extremely interesting for research on language, cognition and social functions, because they display an unusual profile of strengths and weaknesses that may be linked to the genetic alterations responsible for this syndrome. But they are not language savants, and do not provide evidence for intact language in the absence of measurable intelligence.

In short, contrary to your reviewer, we believe that Karmiloff and KarmiloffSmith 'got it right'.

Elizabeth Bates ${ }^{\star}$, Helen Tager-Flusberg $\dagger$, Stefano Vicarił, Virginia Volterra $\$$

${ }^{*}$ Center for Research in Language 0526, University of California, San Diego, 9500 Gilman Drive, La Jolla, California 92093, USA

$\dagger$ Laboratory of Developmental Cognitive Neuroscience, Department of Anatomy and Neurobiology, Boston University School of Medicine, 715 Albany Street, Boston, Massachusetts 02118-2526, USA $¥$ Servizio di Neurologia e Riabilitazione, IRCCS, Ospedale Pediatrico Bambino Gesù, Lungomare Guglielmo Marconi 36, I-00058, Santa Marinella, Rome, Italy

\$Istituto di Psicologia, CNR, Viale Marx 15, 00137 Rome, Italy

\section{Concerns highlight need to make faster decisions}

Sir - Your News story "Venture capital concerns academics" (Nature 413, 95; 2001), on the involvement of the
University of California, San Francisco (UCSF) with the Burrill venture fund, suggests a plan hatched by investors and university officials to exploit our faculty without our consent.

The conflicts for faculty and students resulting from university-industry collaborations have been well documented in, for example, The Business-Higher Education Forum's Working Together, Creating Knowledge: The UniversityIndustry Research Collaboration Initiative (American Council on Education, Washington; 2001. http://www.acenet.edu/ bookstore/index.cfm?pubID=230). It would be a pity if articles such as your News story derailed the recent improvements in relations between universities and industries by artificially setting academic scientists against those marketing their discoveries.

The lofty 'bench-to-bedside' goal we aspire to requires that scientists facilitate the transfer of their ideas into the commercial world. At UCSF we scientists, of our own volition, submit about 150 disclosures a year to our Office of Technology. Far too few of these disclosures result in useful products. A committee I chaired identified several contributing factors, including lack of funding for proof-of-principle research and for intellectual-property costs, lack of business acumen among our faculty, and cumbersome procedures. To speed up the process, we developed a non-restrictive agreement with Burrill that we hope will unclog the pipeline with no loss of faculty autonomy or of Burrill's autonomy to set up similar agreements with others.

The agreement introduced no significant changes in the way UCSF operates and required no faculty input. Nonetheless, as a public institution we are especially sensitive to public perception, and so our proposal was offered for comment to several advisory groups, including the Academic Senate, the official voice of the UCSF faculty. Some members of the senate felt that two months was not sufficient time to identify any potential conflicts of interest. It was their dissatisfaction that was reported in your News story. (And as this correspondence goes to press, the proposal seems increasingly unlikely to come to fruition).

You have nicely illustrated a real conflict of interest in industry-academic interactions. Industry needs a hierarchical structure that allows rapid decisions. Universities have a diffuse decisionmaking structure that can be slowed to glacial speeds because of lack of faculty time and diversity of opinion. If university research is truly to benefit society we need to find ways to accommodate faculty decision-making processes to the honest needs of our industrial counterparts. Regis Kelly

Executive Vice Chancellor, UCSF, Department of Biochemistry \& Biophysics, University of California, San Francisco, California 94143, USA

\section{Sound basis for research}

Sir - Your News story "Fears for basic science as Bush backs use of investment criteria" (Nature 413, 5; 2001) expresses concerns over the fate of research funding and policy under the Bush administration, owing to the establishment of researchand-development performance criteria. The Bush administration is indeed examining explicit criteria for federal investment in research according to its President's Management Agenda.

This initiative was prompted by two excellent reports by the Committee on Science, Engineering, and Public Policy (COSEPUP) - Evaluating Federal Research Programs: Research and the Government Performance and Results Act (1999; see http://books.nap.edu/html/gpra) and Implementing the Government Performance and Results Act for Research (2001; see http://books.nap.edu/html/gpra2) — and by other observations from the scientific community, such as the US House of Representatives Committee on Science 1998 report Unlocking Our Future: Toward a New National Science Policy (http://www.house. gov/science/science_policy_report.htm). The administration's efforts will start with applied research programmes, and apply the lessons learned to the evaluation of basic science. The administration supports explicit criteria for the quality, relevance and appropriate federal role of projects, rather than basing funding levels on vague anecdotes and previous-year funding levels.

The administration does not believe all basic research should be done by industry, nor are we developing criteria in isolation with merely 'green-eyeshade' views of research investments. We fully understand the difficulties of applying performance measures to basic research programmes, but this does not exclude good management and high performance. We have had extensive consultations with COSEPUP, the Office of Science and Technology Policy, members of Congress and their staff, and other leading researchers. These have provided useful insights that we are incorporating into our work.

The National Academy of Sciences has laid a foundation for us. We invite the scientific community to continue to work with us as we tackle the difficult task of implementing these sound ideas.

Mitchell E. Daniels, Jr

Director, Office of Management and Budget, 725

17th Street NW, Washington, DC 20009, USA 